\title{
Climate Change in Urban Areas: A Case Study of Mysuru City
}

\author{
Geethalakshmi S and K. C. Manjunath \\ Department of Civil Engineering, The National Institute of Engineering, Mysuru, India \\ Corresponding author email: geethalakshmi314@gmail.com
}

\begin{abstract}
In climate change research studies, trend analysis has played a remarkable role for almost the past 3 decades. The study aims to find out the variations in climate parameters for Mysuru City. The climate variables were examined for annual and seasonal trends for Mysuru City for the period 1980-2020. To determine the increasing or decreasing trend in climate data along with their statistical significance, both parametric test (linear regression) and non-parametric tests (MannKendall and Sen's method) were used. In the current study, the statistically significant increasing trends were detected in annual, winter, and monsoon maximum temperature series and annual and monsoon minimum temperature series. Besides tmax and tmin during summer and tmin in winter does not show any discernible trend. The annual and summer rainfall and relative humidity during summer show a significant increasing trend.
\end{abstract}

\section{KEY WORDS: CLIMATE CHANGE, STATISTICAL SIGNIFICANCE, CLIMATE VARIABLES.}

\section{INTRODUCTION}

Climate change, in general, ascribed to the intensification of greenhouse gas emission and anthropogenic activities have a consequential effect on hydro-meteorological variables, which includes runoff, precipitation, streamflow, temperature, soil moisture, and relative humidity, and their effects manifest as sudden jumps or trends (Mehan et al., 2016; Sen, 2012; Yilmaz et al., 2020). As a result of greenhouse gas emissions, the warming of our planet is presently indisputable and in comparison to the preindustrial period, the earth has warmed by $0.74^{\circ} \mathrm{C}$ due to a large rise in $\mathrm{CO} 2$ concentration in the atmosphere (Asfaw et al., 2018; Toprak et al., 2013b). Average global surface temperatures are predicted to increase by around $0.4-5.8^{\circ} \mathrm{C}$ by the end of the century, potentially affecting ecosystems and the Earth's hydrologic cycle (Mooij et al., 2007; Shetkar \&t Mahesha, 2011).

Climate change is wreaking havoc on small-scale subsistence farmers on account of their low adaptive ability and their reliance on rain-fed agriculture, which

Biosc Biotech Res Comm P-ISSN: 0974-6455 E-ISSN: 2321-4007

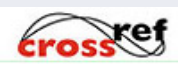

Identifiers and Pagination

Year: 2021 Vol: 14 No (5) Special Issue

Pages: 277-282

This is an open access article under Creative

Commons License Attribn 4.0 Intl (CC-BY).

DOI: http://dx.doi.org/10.21786/bbrc/14.5/50 is more climate-sensitive (Asfaw et al., 2018). In an agricultural-dependent country like India climate change remarkably affects the economy of the country to a notable extent. The frequency and severity of extreme events have risen significantly as a result of climate change (Intergovernmental Panel on Climate Change 2007).

The existence of a deterministic trend in the examined time series reveals knowledge on future development or changes in the process (Sen, 2014; Toprak et al., 2013a). With the increasing importance of climate change assessment, trend identification has become a focus of research (Brunetti et al., 2001; Burn \&t Hag Elnur, n.d.; Sen, 2014; Toprak et al., 2013b). To explore climate change scenarios and magnify climate impact research, trend identification is a useful area of study for both hydrology and climatology (Cryosphere et al., 2013; Karpouzos et al., 2010). The current study aims to investigate the impact of climate change on hydrometeorological variables such as precipitation, temperature, and relative humidity for Mysuru City by investigating the existence of a significant trend.

Study Area: Mysuru is located on the southern tip of the Karnataka state and it is the second-largest city in the state, situated at $12^{\circ} 15^{\prime}$ to $12^{\circ} 21^{\prime}$ North latitude and $76^{\circ} 36^{\prime}$ to $76^{\circ} 42^{\prime}$ East longitude having an elevation of $770 \mathrm{~m}(2530 \mathrm{ft})$ from the mean sea level covering an area of $286 \mathrm{sq}$. km. The city is bordered by the states of

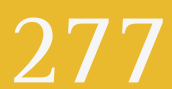


Kerala, Tamilnadu and is flanked by the state cities of Chamarajanagar, Mandya, and Mercara. The city has the Kaveri river flowing to the north and Kabini to the south. According to the Koppen climate classification, Mysuru has a tropical savanna climate (Aw). The average annual rainfall of the city is $800 \mathrm{~mm}$.

3. Database: The data used for the study include precipitation data records for Mysuru City collected from the Indian Meteorological Department. Temperature and relative humidity data records from National Centers for Environmental Prediction spanning from 1980 to 2020 and covers 40 years. Mysuru City is considered to have 3 distinct seasons; summer lasts from March to May, monsoon lasts from June to October, and winter lasts from November to February. The City has prolonged summer and shortened winter season, a part of the summer season is considered as monsoon due to a greater number of rainy days.

\section{METHODOLOGY}

The data obtained is thoroughly checked and screened. The temporal trends of rainfall, temperature, and relative humidity were analyzed using the parametric test (linear regression) and non-parametric tests (MannKendall (MK) trend test, and Sen's estimator of slope). A linear trend line was fitted to examine the increasing/ decreasing trend in a time series using the least square curve fitting. The significant trend in the time series data was determined using the MK trend test and Sen's estimator of slope was used to quantify the trend obtained from the MK trend test. The linear trend in the time-series was determined using Microsoft Excel and to analyze the existence of significant trends in the time series MK trend test and Sen's test was performed using XLSTAT software.

Linear Regression Analysis: The parametric test is based on the least square principle. The least-square curve fitting technique was used to fit linear trends in the time series data. The linear trend between the climate data (Y) and time $(\mathrm{X})$ is given by the following equation.

$\mathrm{Y}=\mathrm{A}+\mathrm{B}(\mathrm{X})$

Where $\mathrm{Y}$ is the climate data at time $\mathrm{X}$. B is the computed slope coefficient out of the record series. The increasing/ decreasing trends in the climate data are determined by the positive/negative value of the slope coefficient.

Mann-Kendall (MK) Trend Test: The most widely accepted non-parametric test is the MK trend test, which determines the presence of significant trends in the time series data. The MK test statistic $S$ is given by the formula.

$$
S=\sum_{k=1}^{n-1} \sum_{j=k+1}^{n} \operatorname{sgn}\left(b_{j}-b_{k}\right)
$$

Where $b_{j}$ and $b_{k}$ are measurements obtained at time $j$ and $\mathrm{k}, \mathrm{n}$ is the number of observations.
The function sgn $\left(b_{j}-b_{k}\right)$ is computed by

$$
\operatorname{sgn}\left(b_{j}-b_{k}\right)=\left\{\begin{array}{c}
+1 \text { if }\left(b_{j}-b_{k}\right)>0 \\
0 \text { if }\left(b_{j}-b_{k}\right)=0 \\
-1 \text { if }\left(b_{j}-b_{k}\right)<0
\end{array}\right.
$$

The statistic $\mathrm{S}$ is asymptotically normal when $\mathrm{n} \geq 8$ having mean zero and variance computed by the formula.

$$
\operatorname{Var}(S)=\frac{\left[n(n-1)(2 n+5)-\sum_{p=1}^{m} c_{p}\left(c_{p}-1\right)\left(2 c_{p}+5\right)\right]}{18}
$$

where $\mathrm{m}=$ number of tied groups

$c_{p}=$ number of data points in the tied group

The Mann-Kendall $\mathrm{Z}$ is computed by the formula

$$
Z_{\mathrm{S}}=\left\{\begin{array}{l}
\frac{s-1}{\sqrt{\operatorname{Var}(s)}} \text { if } s>0 \\
0 \text { if } s=0 \\
\frac{s+1}{\sqrt{\operatorname{Var}(s)}} \text { if } s<0
\end{array}\right.
$$

The positive/negative value of the $z$ signifies the increasing/decreasing trend in the time series. The null hypothesis $\left(\mathrm{H}_{0}\right)$ of no significant monotonic trend in the time series data is accepted if $\left.-z_{1}-\alpha /{ }_{2}\right) \leq z \leq z_{1}-\alpha /{ }_{2}$ ) at the user-specified significance level of $\alpha$. Otherwise, the alternate hypothesis of having a significant trend at the significance level is accepted.

4.3 Sen's Slope Estimator: Sen's slope estimator is used to measure the trend obtained from MK trend test. The slope of all the time series data pairs is given by the formula (Sen, 1968).

$$
B_{i}=\frac{\left(a_{u}-a_{v}\right)}{u-v}
$$

Where $\mathrm{a}_{\mathrm{u}}$ and $\mathrm{a}_{\mathrm{v}}$ are data values corresponding to $\mathrm{u}$ and $\mathrm{v}(\mathrm{u}>\mathrm{v})$ respectively.

\section{RESULTS AND DISCUSSION}

5.1 Maximum Temperature $\left(\mathrm{t}_{\max }\right)$ : The maximum temperature for the city varied in the range of $26^{\circ} \mathrm{C}$ in monsoon to $30^{\circ} \mathrm{C}$ in summer with a mean value of $28^{\circ} \mathrm{C}$. The standard deviation (SD) of the maximum temperature for the study area varied in the range $0.42^{\circ} \mathrm{C}$ to $0.55^{\circ} \mathrm{C}$ with the coefficient of variation (CV) ranging from $1.51 \%$ to $1.88 \%$ (Table 1 ). The $\mathrm{CV}$ for winter was relatively less compared to annual, summer, and monsoon. The $\mathrm{t}_{\max }$ time series were analyzed using a linear regression 
model and the rate of change is defined by the slope of the regression line (Asfaw, 2018). The outcomes of the regression analysis show that the annual, winter, and monsoon maximum temperatures show an increasing trend excluding the summer season, where a decreasing trend can be observed (Fig 1). As shown in Table 2 the results of MK trend test revealed that tmax for annual, winter, and monsoon seasons have been increasing from 1980 to 2020 significantly at a 95\% confidence interval. The summer maximum temperatures also show a decreasing trend, but not statistically significant. The obtained results from Sen's estimator of slope for the period 1980-2020 (Table 2) revealed a high degree of similarity between the results obtained using the Mann-Kendall trend test, linear regression, and Sen's slope method.

\begin{tabular}{|c|c|c|c|c|c|}
\hline & Statistic & Annual Average & Winter & Summer & Monsoon \\
\hline \multirow[t]{4}{*}{$\begin{array}{l}\text { Maximum Temperature } \\
\text { in }{ }^{\circ} \mathrm{C}\end{array}$} & Range & $27-28$ & $27-28$ & $29-30$ & $26-27$ \\
\hline & Mean & 28 & 28 & 30 & 26 \\
\hline & SD & 0.50 & 0.42 & 0.55 & 0.49 \\
\hline & CV (\%) & 1.83 & 1.51 & 1.88 & 1.86 \\
\hline \multirow{4}{*}{$\begin{array}{l}\text { Minimum } \\
\text { Temperature } \\
\text { in }{ }^{\circ} \mathrm{C}\end{array}$} & Range & $24-25$ & $23-24$ & $25-26$ & $24-25$ \\
\hline & Mean & 24 & 24 & 26 & 24 \\
\hline & SD & 0.42 & 0.5 & 0.5 & 0.22 \\
\hline & CV (\%) & 1.73 & 2.11 & 1.97 & 0.91 \\
\hline \multirow{4}{*}{$\begin{array}{l}\text { Rainfall in } \\
\mathrm{mm}\end{array}$} & Range & 428-1604 & $5-651$ & $73-402$ & $45-868$ \\
\hline & Mean & 818 & 87 & 212 & 236 \\
\hline & SD & 250 & 114 & 77 & 165 \\
\hline & CV (\%) & 30.58 & 131.78 & 36.79 & 70.07 \\
\hline \multirow{4}{*}{$\begin{array}{l}\text { Relative Humidity in } \\
\%\end{array}$} & Range & $75-82$ & $61-73$ & $66-80$ & $88-94$ \\
\hline & Mean & 78 & 65 & 71 & 91 \\
\hline & SD & 1.39 & 2.55 & 2.93 & 1.49 \\
\hline & $\mathrm{CV}(\%)$ & 1.78 & 3.91 & 40.86 & 1.64 \\
\hline
\end{tabular}

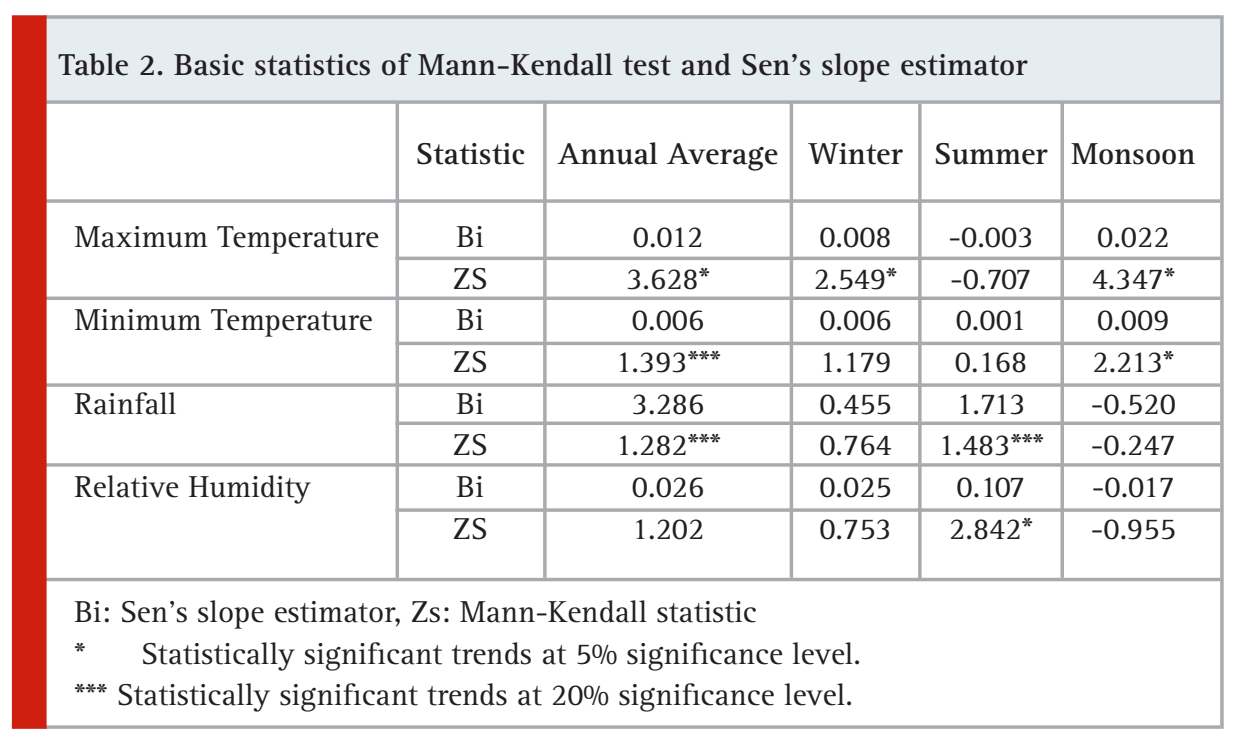

5.2 Minimum Temperature $\left(t_{\text {min }}\right)$ : The $t_{\text {min }}$ for the city varied in the range of $23^{\circ} \mathrm{C}$ in winter to $26^{\circ} \mathrm{C}$ in summer with a mean value of $24^{\circ} \mathrm{C}$. The SD of the $t_{\text {min }}$ for the study area varied in the range $0.22^{\circ} \mathrm{C}$ to $0.5^{\circ} \mathrm{C}$ with CV ranging from $0.91 \%$ to $2.11 \%$. The coefficient of variation was relatively less in monsoon compared to other seasons (i.e., annual, summer, winter). The results of regression analysis for minimum temperature show a fragile upward trend for both annual and seasonal scales. The monsoon tmin and annual tmin reveal +ve trend, which is statistically significant at 5\% and 15\% significance levels. 
Figure 1: Linear trend analysis of maximum and minimum temperature for the period 1980-2020
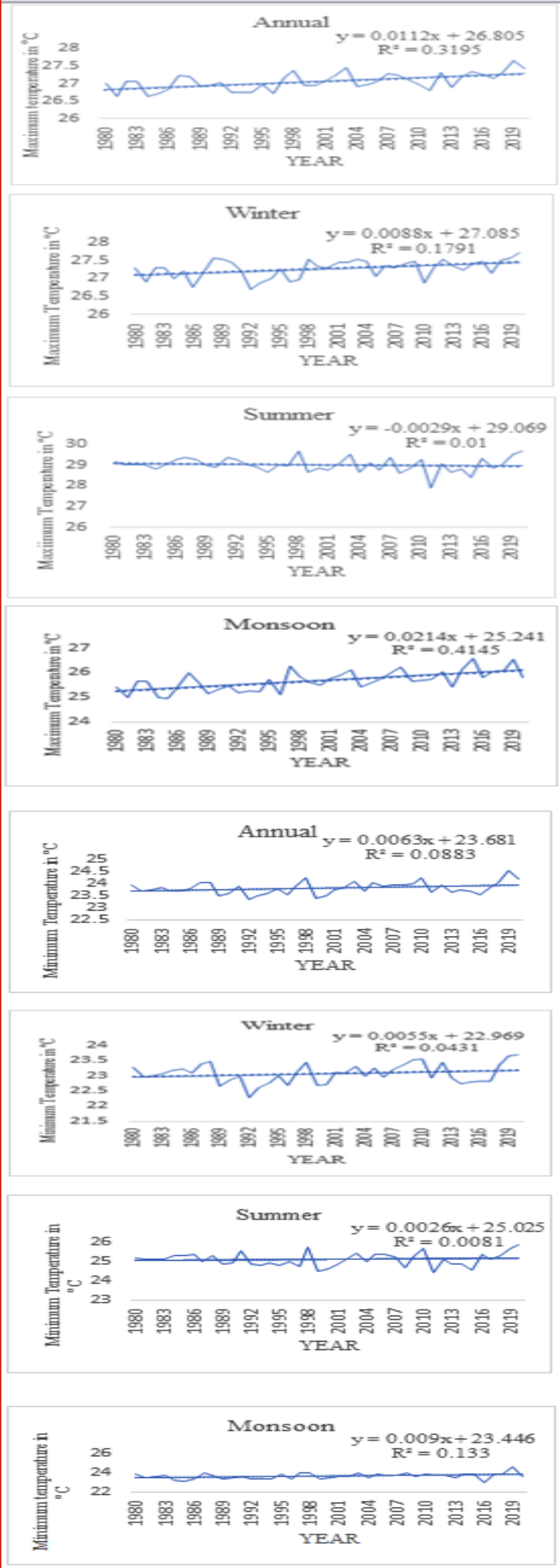

Figure 2: Linear trend analysis of rainfall and relative humidity for the period 1980-2020
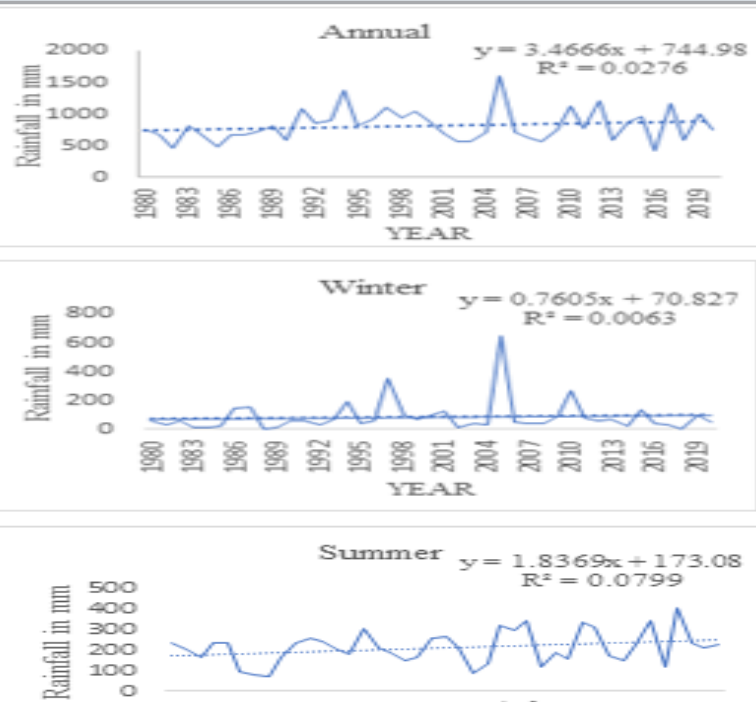

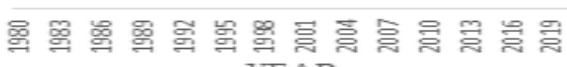
YEAR

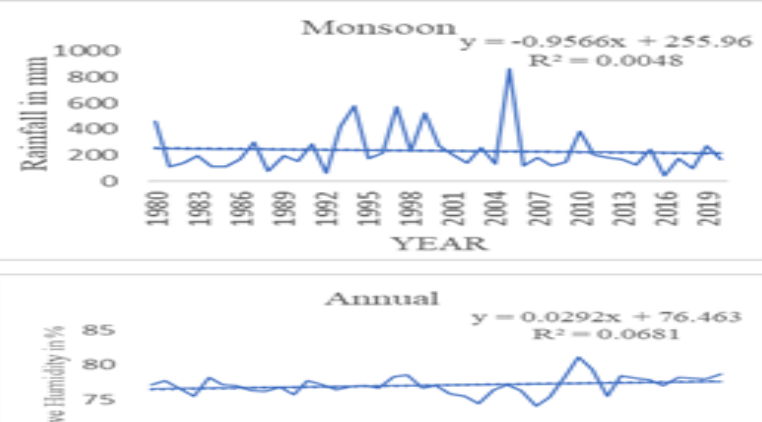

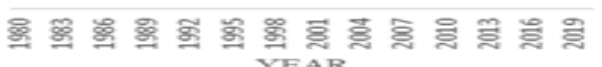
YEAR
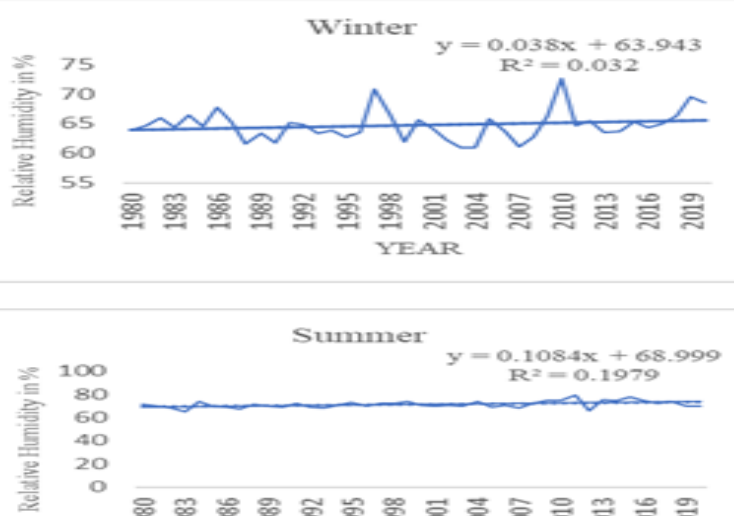

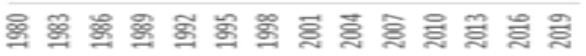
YEAR

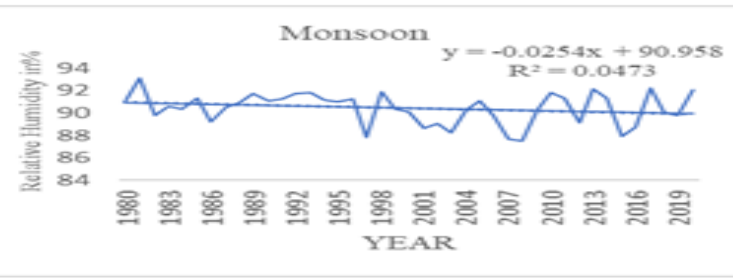


The obtained results are compatible with a similar study by researchers at the Indian Institute of Science (IISc), Banglore(Sonali \&t Nagesh Kumar, 2013) which detected that the faster rise in minimum temperature trend compared to maximum temperature over most parts of India can be attributed to natural climate variability.

5.3 Rainfall: The rainfall value for the city varied in the range of $5 \mathrm{~mm}$ in winter to $868 \mathrm{~mm}$ in monsoon with an average of $818 \mathrm{~mm}$. The SD of rainfall for the study area varied in the range of $77 \mathrm{~mm}$ to $250 \mathrm{~mm}$ with CV ranging from $30.58 \%$ to $131.78 \%$. The CV was relatively more in winter compare to annual, summer, and monsoon scales. The corresponding regression line is also plotted for the rainfall time series (Fig 3). The positive trends are evident with annual, winter, and summer scales excluding monsoon rainfall, which shows a negative trend. The annual and summer rainfall shows a $+\mathrm{v}$ trend, which is statistically significant at a $20 \%$ significance level as shown in Table 2, whereas winter and monsoon rainfall does not reveal a statistically significant trend.

5.4 Relative Humidity (RH): The relative humidity for the city varied in the range of $61 \%$ in winter to $94 \%$ in monsoon with a mean value of $78 \%$. The SD and CV for $\mathrm{RH}$ vary in the range $1.39 \%$ to $2.93 \%$ and $1.78 \%$ to $40.86 \%$ as shown in Table 1 . The CV for the summer season is more compared to other seasons. The linear trend analysis for the $\mathrm{RH}$ time series indicates that the annual, winter and summer RH reveals a +ve trend (Fig 2), whereas monsoon relative humidity shows the -ve trend. The outcomes of the MK trend test (Table 2) portrayed that the RH for the summer season has been increasing for the period 1980-2020.

\section{CONCLUSION}

The results of this study led to the following findings:

- The results of maximum temperature trends clearly show an increasing trend on an annual scale. The warming trend has been noticed in the winter and monsoon season, whereas the -ve trend is revealed for the summer season. The exact reason for the phenomenon can be attributable to the increase in anthropogenic activities leading to global warming. The atmosphere is stable during the winter months. As a result, there will be a more pronounced impact of anthropogenic activities causing more warming in the winter months.

- The analysis of minimum temperature trends revealed the increasing trend of minimum temperature both in annual and seasonal scales. Minimum temperatures are showing pronounced increasing trends as that of maximum temperatures for the city were evident from the results.

- The use of the trend analysis context to the rainfall time series for the study area has resulted in declining trends of monsoon rainfall and increasing trends of annual, summer, and winter rainfall. The declining trend of the city's monsoon may indicate an influence of urbanization on precipitation linked with enhanced anthropogenic activities due to urban expansion and population growth.

- The outcomes of trend analysis revealed that the relative humidity shows + ve trend for annual, winter, and summer for the city and the decreasing trend during monsoon season.

\section{REFERENCES}

Ahn, Kuk-Hyun, and Richard N. Palmer. "Trend and variability in observed hydrological extremes in the United States."Journal of Hydrologic Engineering 21.2 (2016): 04015061.

Asfaw, Amogne, et al. "Variability and time series trend analysis of rainfall and temperature in northcentral Ethiopia: A case study in Woleka sub-basin.” Weather and climate extremes 19 (2018): 29-41.

Basistha, Ashoke, D. S. Arya, and N. K. Goel. "Analysis of historical changes in rainfall in the Indian Himalayas." International Journal of Climatology: A Journal of the Royal Meteorological Society 29.4 (2009): 555-572.

Bothale, Rajashree Vinod, and Yashwant B. Katpatal. "Trends and anomalies in extreme climate indices and influence of El Niño and La Niña over Pranhita catchment in Godavari Basin, India.” Journal of Hydrologic Engineering 21.2 (2016): 05015023.

Brunetti, Michele, Maurizio Maugeri, and Teresa Nanni. "Changes in total precipitation, rainy days and extreme events in northeastern Italy." International Journal of Climatology: A Journal of the Royal Meteorological Society 21.7 (2001): 861-871.

Burn, Donald H., and Mohamed A. Hag Elnur. "Detection of hydrologic trends and variability." Journal of hydrology 255.1-4 (2002): 107-122.

Chen, Sichun, et al. "Spatiotemporal changes in precipitation and temperature in the Huaibei plain and the relation between local precipitation and global teleconnection patterns." Journal of Hydrologic Engineering 24.8 (2019): 05019019.

Douglas, E. M., R. M. Vogel, and C. N. Kroll. ”Trends in floods and low flows in the United States: impact of spatial correlation.” Journal of hydrology 240.1-2 (2000): 90-105.

Groisman, Pavel Ya, et al. "Contemporary changes of the hydrological cycle over the contiguous United States: Trends derived from in situ observations.” Journal of hydrometeorology 5.1 (2004): 64-85.

Karpouzos, D. K., Sofia Kavalieratou, and Christos Babajimopoulos. "Trend analysis of precipitation data in Pieria Region (Greece)." European Water 30.30 (2010): 
30-40.

Liuzzo, Lorena, and Gabriele Freni. "Analysis of extreme rainfall trends in Sicily for the evaluation of depth-duration-frequency curves in climate change scenarios." Journal of Hydrologic Engineering 20.12 (2015): 04015036.

Mehan, Sushant, et al. "Climate change impacts on the hydrological processes of a small agricultural watershed." Climate 4.4 (2016): 56.

Mondal, Arun, Deepak Khare, and Sananda Kundu. "Spatial and temporal analysis of rainfall and temperature trend of India." Theoretical and applied climatology 122.1 (2015): 143-158.

Mooij, Wolf M., et al. "Predicting the effect of climate change on temperate shallow lakes with the ecosystem model PCLake." Shallow Lakes in a Changing World. Springer, Dordrecht, 2007. 443-454.

Radhakrishnan, Kalidoss, et al. "A climate trend analysis of temperature and rainfall in India." Climate Change and Environmental Sustainability 5.2 (2017): 146-53. Sharma, Shilpy, David A. Swayne, and Charlie Obimbo. "Trend analysis and change point techniques: a survey." Energy, Ecology and Environment 1.3 (2016): 123130.

Sonali, P., and D. Nagesh Kumar. "Review of trend detection methods and their application to detect temperature changes in India." Journal of Hydrology 476 (2013): 212-227.

Thenmozhi, M., and S. V. Kottiswaran. "Analysis of rainfall trend using Mann-Kendall test and the Sen's slope estimator in Udumalpet of Tirupur district in Tamil Nadu." International journal of agricultural science and research 6.2 (2016): 131-138.

Toprak, Z. Fuat, et al. "Climatic identity assessment of the climate change." International Journal of Global Warming 5.1 (2013): 30-45.

Wang, Wenpeng, et al. "Variance correction prewhitening method for trend detection in autocorrelated data." Journal of Hydrologic Engineering 20.12 (2015): 04015033.

Yilmaz, Muhammet, Fatih Tosunoglu, and Nur Hüseyin Kaplan. "Evaluation of Trends and Dominant Modes in Maximum Flows in Turkey Using Discrete and Additive Wavelet Transforms.” Journal of Hydrologic Engineering 25.11 (2020): 05020037.

Yogananda, S. B., G. K. Shruthi, and P. Thimme Gowda. "Rainfall trend analysis of Mysore district in Karnataka." International Journal of Recent Research in Interdisciplinary Sciences 2 (2015): 11-15 